\title{
Intranasal Dantrolene as a Disease-Modifying Drug in Alzheimer 5XFAD Mice
}

\author{
Yun Shi ${ }^{\mathrm{a}, \mathrm{b}}$, Lei Zhang ${ }^{\mathrm{a}, \mathrm{c}}$, Xue Gao $^{\mathrm{a}, \mathrm{d}}$, Jing Zhang ${ }^{\mathrm{a}, \mathrm{e}}$, Matan Ben Abou ${ }^{\mathrm{a}}$, Ge Liang ${ }^{\mathrm{a}}$, \\ Qingcheng Meng ${ }^{\mathrm{a}}$, Adrian Hepner ${ }^{\mathrm{f}}$, Maryellen F. Eckenhoff ${ }^{\mathrm{a}}$ and Huafeng Wei ${ }^{\mathrm{a}, *}$ \\ ${ }^{a}$ Department of Anesthesiology and Critical Care, Perelman School of Medicine, University of Pennsylvania, \\ Philadelphia, PA, USA \\ ${ }^{\mathrm{b}}$ Department of Anesthesiology, Children's Hospital of Fudan University, Shanghai, China \\ 'Department of Anesthesiology, People's Hospital of Beijing Daxing District, Beijing, China \\ ${ }^{\mathrm{d}}$ Department of Anesthesiology, Beijing Friendship Hospital, Capital Medical University, Beijing, China \\ ${ }^{\mathrm{e}}$ Department of Anesthesiology, Beijing Shijitan Hospital, Capital Medical University, Beijing, China \\ ${ }^{\mathrm{f}}$ Eagle Pharmaceuticals, Inc., Woodcliff Lake, NJ, USA
}

Handling Associate Editor: Tao Ma

Accepted 22 May 2020

\begin{abstract}
.
Background/Objective: This study compares the effectiveness and safety of intranasal versus subcutaneous administration of dantrolene in 5XFAD Alzheimer's disease (AD) mice.

Methods: 5XFAD and wild type (WT) B6SJLF1/J mice were treated with intranasal or subcutaneous dantrolene $(5 \mathrm{mg} / \mathrm{kg}$, $3 \times / \mathrm{wk}$ ), or vehicle. The early (ETG) and late (LTG) treatment groups began treatment at 2 or 6 months of age, respectively, and both treatment groups finished at 12 months of age. Behavior was assessed for olfaction (buried food test), motor function (rotarod), and cognition (fear conditioning, Morris water maze). Liver histology (H \& E staining) and function, synaptic proteins, and brain amyloid immunohistochemistry were examined. Plasma and brain dantrolene concentrations were determined in a separate cohort after intranasal or subcutaneous administration.

Results: Intranasal dantrolene achieved higher brain and lower plasma concentrations than subcutaneous administration. Dantrolene administration at both approaches significantly improved hippocampal-dependent and -independent memory in the ETG, whereas only intranasal dantrolene improved cognition in the LTG. Dantrolene treatment had no significant change in the amyloid burden or synaptic proteins and no significant side effects on mortality, olfaction, motor, or liver functions in 5XFAD mice. Intranasal dantrolene treatment significantly ameliorated memory loss when it was started either before or after the onset of AD symptoms in 5XFAD mice.

Conclusions: The long-term intranasal administration of dantrolene had therapeutic effects on memory compared to the subcutaneous approach even started after onset of AD symptoms, suggesting use as a disease-modifying drug, without significant effects on amyloid plaques, side effects, or mortality.
\end{abstract}

Keyword: Alzheimer's disease, cognitive dysfunction, dantrolene, intranasal administration

\footnotetext{
${ }^{*}$ Correspondence to: Huafeng Wei, MD, PhD, Department of Anesthesiology and Critical Care, University of Pennsylvania Perelman School of Medicine, 305 John Morgan Building, 3620
}

Hamilton Walk, Philadelphia, PA 19104, USA. Tel.: +1 215746 8704; Fax: +1 215349 5078; E-mail: weih@uphs.upenn.edu. 


\section{INTRODUCTION}

Alzheimer's disease (AD) is the most common form of dementia and has increasingly become a significant burden on society due to its high incidence and growing mortality rate. The incidence of $\mathrm{AD}$ is increasing and currently ranked as the sixth leading cause of death in the United States, while other diseases, such as cancer and heart disease, are decreasing [1]. While there is a great need to develop an effective therapy for $\mathrm{AD}$, unfortunately, despite the decades of efforts to develop new drugs mainly targeting amyloid pathology, almost all new drug developments have failed [2].

Ryanodine receptors (RyRs), the $\mathrm{Ca}^{2+}$-release channels located on the membrane of the endoplasmic reticulum (ER) which play an important role in cellular and synaptic function, are abnormally increased in AD patients [3] and animal models of AD [4]. Modulation of the RyR has been considered as a new approach for AD treatment [5]. Dantrolene, an antagonist of the RyR, is the only effective drug known to treat malignant hyperthermia, a lifethreatening hypermetabolic state in skeletal muscle, by inhibiting the RYR calcium release channels [6]. Chronic oral use of dantrolene is also indicated to treat muscle spasms, with relatively tolerable side effects [7]. Although initially negative effects on AD pathology were shown when dantrolene was used in a familial AD (FAD) animal model [8], increasing studies from various laboratories, including our own, have demonstrated positive therapeutic effects of dantrolene to ameliorate memory loss in different FAD animal models $[9,10]$. However, the neuroprotective effect was typically detected when dantrolene was administered after the onset of AD neuropathology and/or symptoms.

When a drug is used to treat a progressive neurologic disease, it is important to keep consistent and sustained brain concentrations to achieve efficacy. The ability of dantrolene to cross the blood-brain barrier (BBB) and maintain efficient CNS exposure, when it is administered subcutaneously [9, 11, 12] or orally $[13,14]$ is controversial. It is generally believed that oral or subcutaneous delivered dantrolene can penetrate the CNS with limitations $[11,15]$. Intranasal drug administration, on the other hand, has demonstrated improved penetration into the CNS with this direct nose to brain pathway [16, 17]. For example, intranasal administration of insulin has been recently investigated as a potential therapy for $\mathrm{AD}$ in human clinical trials [18].
The side effects of chronically administered therapeutic drugs also need to be considered. Chronic oral use of dantrolene can result in liver injury because of its extensive hepatic metabolism [19]. which may limit its potential as a therapeutic drug for AD. However, the studies of intranasal delivery of insulin in humans, have shown an absence of severe side effects [18].

This study investigates the efficacy of intranasal dantrolene administration as a therapeutic agent for the treatment of $\mathrm{AD}$, not only as a symptom-relieving drug but also as a disease-modifying drug.

\section{MATERIALS AND METHODS}

\section{Animals}

All the procedures were approved by the Institutional Animal Care and Use Committee (IACUC) at the University of Pennsylvania. Two pairs of 5XFAD mice (B6SJL-Tg (APPSwFIL on, PSEN1*M146L*L286V) 6799Vas/Mmjax) and wild type mice (B6SJLF1/J) were purchased from the Jackson Laboratory (Bar Harbor, ME) and bred. These 5XFAD transgenic mice over express mutant human APP with the Swedish (K670N, M671L), Florida (I716V), and London (V717I) Familial Alzheimer's Disease (FAD) mutations along with human PS1 harboring two FAD mutations, M146L and L286V [20]. The 5XFAD mouse model is an aggressive AD model with intracellular amyloid first appearing at 2 months of age [20] and cognitive dysfunction beginning at 6 months of age [21], which is suitable to test drug efficacy [22]. Animals were housed in the animal facility of the University of Pennsylvania, under a $12 \mathrm{~h}$ light cycle and controlled room temperature. Food and water were available in the cage. All mice were weaned no later than one month of age and genetically identified by polymerase chain reaction (PCR) analysis before weaning. At this time, mice were divided into different cages according to age and gender, with no more than 5 mice per cage. Both male and female mice were used in this study.

\section{Dantrolene administration}

Dantrolene (Sigma, St Louis, MO) was dissolved in the vehicle $(125 \mathrm{mg}$ mannitol, $25 \mathrm{mg}$ polysorbate $80,4 \mathrm{mg}$ povidone $\mathrm{K} 12$ in $5 \mathrm{~mL}$ of sterile water and $\mathrm{pH}$ adjusted to 10.3), the same vehicle used for RYANODEX ${ }^{\circledR}$ (dantrolene sodium, Eagle 
Pharmaceuticals, Inc., NJ, USA). For intranasal and subcutaneous administration, the final concentration of dantrolene was $5 \mathrm{mg} / \mathrm{mL}$ and $1 \mathrm{mg} / \mathrm{mL}$, respectively. For intranasal administration, the mice were held and fixed by the scruff of their necks with one hand and with the other hand given a total of $1 \mu \mathrm{L} / \mathrm{gram}$ of body weight of dantrolene solution or vehicle. A mouse weighing $20 \mathrm{~g}$ would be given $20 \mu$ l solution. The solution was slowly delivered directly into the mouse's nose, as described previously [23]. Care was taken to make sure that mice were minimally stressed, and that the solution stayed in the nasal cavity and did not enter the stomach or lungs. Subcutaneous dantrolene administration was performed as previously described [11] with a total subcutaneous injection of $5 \mu$ lper gram of body weight.

\section{Dantrolene brain and plasma concentrations}

Wild type mice at 2 months of age were given subcutaneous or intranasal dantrolene at the dose of $5 \mathrm{mg} / \mathrm{kg}$ for one time. At 20 and $60 \mathrm{~min}$ after drug administration, the mice were euthanized (see below) and plasma and brain tissues were obtained. The concentrations of dantrolene in the plasma and brain were determined by high-performance liquid chromatography (HPLC) using an Agilent Hewlett Packard Model 1100 Series as we have previously described [11, 24]. Briefly, the frozen brain tissue was placed into $200 \mu \mathrm{l}$ of mixture solution (acetonitrile: $\mathrm{H}_{2} \mathrm{O}, 2: 1$ ) and homogenized, the suspensions were then centrifuged at $4^{\circ} \mathrm{C}$ at $20,000 \times \mathrm{g}$ for $20 \mathrm{~min}, 50 \mu \mathrm{l}$ of supernatant was injected into HPLC for analysis. Acetonitrile was used as component A of the mobile phase, and potassium phosphate buffer solution $(\mathrm{pH}$ 7.0) as component B. The mobile phase had a flow rate of $1.0 \mathrm{~mL} / \mathrm{min}$ with a proportion of $12 \%$ to $88 \%$ for components $\mathrm{A}$ and $\mathrm{B}$ of the mobile phase, respectively. Detection was performed with the UV detector at $254 \mathrm{~nm}$. We did not precipitate protein from the brain or plasma.

\section{Dantrolene treatment groups}

Age-matched male and female mice were randomly divided into experimental groups when they were genotyped around 1 month of age (Fig. 1). The Early Treatment Groups (ETG), including intranasal dantrolene (IN-DAN), subcutaneous dantrolene (SQDAN), intranasal vehicle (IN-VEH), and no treatment (CON, negative control), were treated once a day,

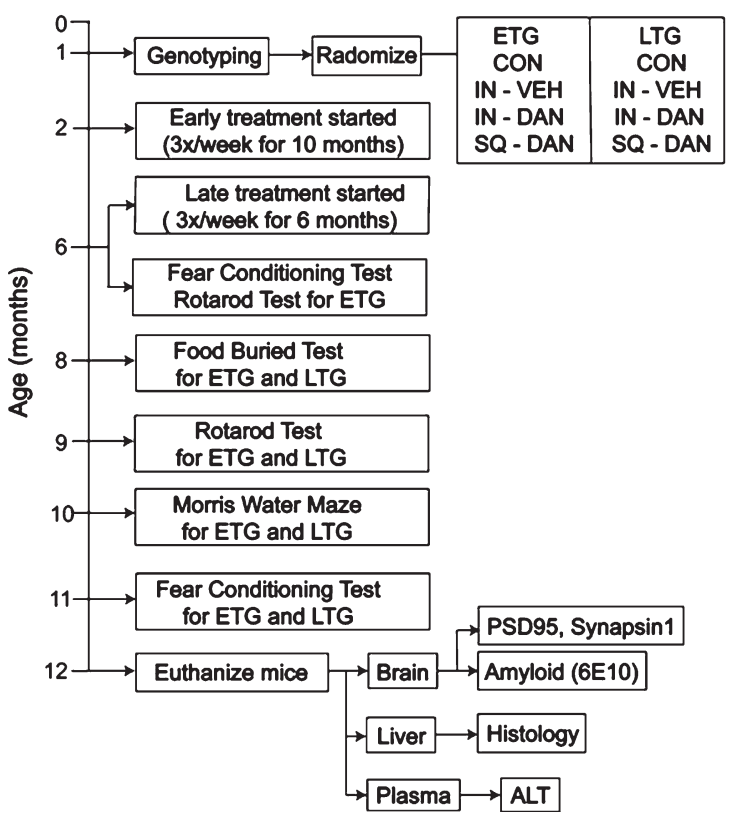

Fig. 1. Experimental design. Timeline for treatments, behavioral tests, and euthanasia. Twelve experimental groups were designed based on genotype (5XFAD, WT), age when treatment began (Early Treatment (ETG), Late Treatment (LTG) groups), and the administration route of dantrolene (Intranasal, Subcutaneous).

$3 \times /$ week (Monday, Wednesday, and Friday) beginning at 2 months of age, before the onset of intracellular amyloid pathology and any cognitive dysfunction [20]. The Late Treatment Groups (LTG), intranasal dantrolene (IN-DAN) and subcutaneous dantrolene (SQ-DAN), began the same treatment at 6 months of age, well after the onset of extracellular amyloid plaques accumulation and cognitive dysfunction [20]. The vehicle was made fresh and contained all inactive ingredients in Ryanodex. Fresh dantrolene was made every time before administration with the vehicle for intranasal $(5 \mathrm{mg} / \mathrm{ml})$ and subcutaneous $(1 \mathrm{mg} / \mathrm{ml})$ administration. All mice continued to receive treatment until they were euthanized at 12 months of age.

\section{Food buried test}

Olfaction was assessed in all groups at 8 months of age as previously described with modifications [25]. On the first day, cookies (Galletas La Moderna, S.A. de C.V.; 1 cookie for every 2 mice) were buried in the bedding of the home cages for $24 \mathrm{~h}$, and then the number of cookies consumed was recorded. The mice were fasted starting on the second day at $4 \mathrm{pm}$ and ending on the third day at $9 \mathrm{am}$. Water was freely 
available during this time. The buried food test was conducted on the third day at approximately 9-11 am. They were acclimated to the testing room for at least $1 \mathrm{~h}$ before the test. Mice were individually placed into a clean cage containing clean bedding with one cookie buried beneath the bedding in a corner. The latency for the animal to find the cookie (identified as catching the cookie with its front paws) was recorded manually. If the animal failed to find the cookie within $15 \mathrm{~min}$, it would be placed back into its home cage. A clean cage and bedding were used for each animal and investigators were blinded to the experimental conditions.

\section{Rotarod test}

Motor function was examined for muscle weakness, a common side effect of dantrolene. The amount of time spent on the accelerating rotarod (IITC Series 8, Life Sciences, Woodland Hills, CA) was assessed for mice in the ETG at 6 months of age (data not shown) and for all groups at 9 months of age, as we previously described [11]. Briefly, animals were acclimated to the testing room at least $1 \mathrm{~h}$ before the test. Two $60 \mathrm{~s}$ training trials at a constant speed (9 rpm) were performed with a $30 \mathrm{~min}$ interval. Then, three $120 \mathrm{~s}$ test trials were conducted at a gradually increasing speed $(4-40 \mathrm{rpm})$ with a $60 \mathrm{~min}$ interval between trials. The latency to fall from the rotarod was recorded automatically and analyzed.

\section{Fear conditioning test}

Memory and learning were assessed at 6 and 11 months of age for the ETGs, but only at 11 months of age for LTGs. Both hippocampal-dependent and -independent memory were assessed using the fear conditioning test [26]. Each day, animals were acclimated to the testing room at least $1 \mathrm{~h}$ before the test. On the first day, each mouse was placed in the test chamber and went through three conditionstimulation parings with a $60 \mathrm{~s}$ interval between each cycle. A $30 \mathrm{~s}$ tone of $2000 \mathrm{~Hz}$ and $85 \mathrm{~dB}$ was used as the tone stimulation and a 2-selectrical foot shock of $0.7 \mathrm{~mA}$ was used as the shock stimulation. The mice were removed from the chamber $30 \mathrm{~s}$ after the last stimulation. On the second day, the contextual fear conditioning test was first performed to measure the hippocampal-dependent memory. The mouse was placed in the same chamber for 6 min with no tone or shock and then removed from the chamber. Two hours later, the cued fear conditioning test was performed to measure hippocampal-independent memory. The mouse was placed in another chamber that was different in size and smell using different cleaning solutions. There was no tone or shock during the first $3 \mathrm{~min}$. Later the mouse went through 3 cycles of the same tone with a $60 \mathrm{~s}$ interval between each cycle with the freezing time recorded. Animals were then removed from the chamber $60 \mathrm{~s}$ after the last tone. The ANY-maze controlled Fear Conditioning System consisted of a sound-attenuating chamber (Model: 46000-590, UGO Basile, Gemonio Italy) equipped with a video camera and ANY-maze software (V.4.99 Stoelting Co. Wood Dale, IL) which recorded the freezing time. The chamber was thoroughly cleaned between trials with a $75 \%$ alcohol solution on the first day in the training trials and on the second day in the contextual-fear conditioning test, and with water on the second day in the cuedfear conditioning test. The investigator was blinded to the animal groups.

\section{Morris water maze}

Learning and memory were also measured for all groups at 11 months of age using the Morris water maze (MWM) as we described previously [11]. Briefly, a $1.5 \mathrm{~m}$ diameter pool filled with water and a $15 \mathrm{~cm}$ platform were used throughout the whole test. The water was opacified with titanium dioxide and the temperature was controlled at $21-24^{\circ} \mathrm{C}$. During the first 5 days (day 1 to day 5), the mice went through 4 days of cued trials. The pool was surrounded by a white curtain and the platform was submerged $1-1.5 \mathrm{~cm}$ under the water with a flag on the top as a cue for the mice. The location of the platform and the starting points were random during the cued trials. When the mouse escaped from the pool onto the platform, it was allowed to stay there for $15 \mathrm{~s}$. If the mouse failed to find the platform, the experimenter would gently guide it onto the platform. The latency for each mouse to find the platform was recorded. During the next 5 days (day 6 to day 10), the animals went through 4 place trials every day. The curtain and platform were removed. There were several visual cues on the wall. The location of the platform was fixed, and the starting points were random. The situation of the testing room was kept consistent from then on. Similar to the cued trials, the mouse remained on the platform for $15 \mathrm{~s}$ before it was removed from the pool, or the mouse was guided to the platform if it failed to find the platform within $60 \mathrm{~s}$. The latency for each mouse to find the platform was 
recorded. The mouse went through a probe trial the next day (day 11) in which the platform was removed. The starting point was fixed in the opposite quadrant from where the platform was located. The time each mouse spent in each quadrant was recorded. The ratio of the time each mouse spent in the target quadrant compared to the opposite quadrant was calculated.

\section{Euthanasia and tissue collection}

Mice, for the dantrolene brain and plasma concentration study, were euthanized at 2 months of age and, for the dantrolene treatment groups, at 12 months of age after all the behavior tests were finished. As described previously [11], animals were deeply anesthetized with 2-4\% isoflurane delivered through a nose cone, and the concentration was adjusted according to the animals' response to a toe pinch. The animal's skin was prepped, and an incision made to open the chest and expose the heart. Blood was collected for the plasma study and ALT as says from the heart using a syringe equipped with a $30 \mathrm{G}$ needle. The blood was centrifuged at $3000 \mathrm{rpm}$ at $4^{\circ} \mathrm{C}$ for $10 \mathrm{~min}$, the supernatant collected and frozen at $-80^{\circ} \mathrm{C}$. The plasma samples were protected from light if used for the concentration study. The animals were euthanized by trans cardial perfusion and exsanguination with cold phosphate-buffered saline. The whole brain was dissected for the brain concentration study, which was protected from light and frozen at $-80^{\circ} \mathrm{C}$. For the dantrolene treatment groups, the liver and brain were dissected. The liver and the left half of the brain were post-fixed in $4 \%$ paraformaldehyde overnight at $4{ }^{\circ} \mathrm{C}$ and paraffin-embedded for sectioning. Several animals from each group were randomly selected to be sectioned for the immunohistochemical and histological and studies, and the exact numbers of animals for each assessment are presented in each figure legend. The right half of the brain was frozen at $-80^{\circ} \mathrm{C}$ for biochemical as says.

\section{Immunohistochemistry}

Paraffin-embedded coronal brain sections $(10 \mu \mathrm{m})$ were made for immunohistochemistry as previously described [11]. Briefly, sections were deparaffinized and hydrated. Antigen retrieval was performed in Antigen Unmasking Solution (H3300, Vector Lab, Burlingame, CA) in a pressure cooker. Then the sections were incubated in 10\% normal goat serum for $30 \mathrm{~min}$, in M.O.M Mouse Ig Blocking Reagent (PK2200, Vector Lab) for $1 \mathrm{~h}$, and in M.O.M diluent for $5 \mathrm{~min}$, successively. Slides were incubated with the primary antibody, anti-6E10 $(1: 500,803001$, Bio Legend, San Diego, CA), at $4^{\circ} \mathrm{C}$ over night, followed by incubation with M.O.M Biotinylated Anti-Mouse IgG reagent (PK-2200, Vector Lab) for $10 \mathrm{~min}$ and with VECTASTAIN ABC Reagent (PK7200 , Vector Lab) for $5 \mathrm{~min}$. Then the sections were dehydrated and cover-slipped with Per mount. All images were taken on an Olympus (BX51W1) microscope equipped with a Q Imaging Retiga 2000R digital camera and i Vision imaging software (Bio Vision Technologies, Exton, PA). Cell numbers per area were quantified using Image $J$ software by investigators who were blinded to the groups. The number of plaques per area and the percent area occupied by plaques in the entire hippocampus and dentate gyrus were calculated.

\section{Immunoblotting (western blot)}

The synaptic function was assessed by the expression of related proteins using western blot analysis as we previously described [11]. Briefly, the whole brain homogenate samples were lysed in ice-cold RIPA containing protein inhibitor. The concentration of protein was measured using the Bicinchoninic Acid kit (23227, Thermo Fisher Scientific, Waltham, MA). A mixture of each protein with $4 \mathrm{X}$ loading buffer and $\mathrm{ddH}_{2} \mathrm{O}$ was produced respectively to reach the same volume of the mixture and the same amount of the protein. Equal amounts of sample were loaded on SDS-polyacrylamide gel electrophoresis and transferred to nitrocellulose membrane. The membrane was incubated with 5\% non-fat milk at room temperature for $1 \mathrm{~h}$, followed by incubation with primary antibody, PSD95 (1:500, 810401, Bio Legend, San Diego, CA), synapsin1 (1:500, 515200, Fisher Scientific, Pittsburgh, PA) and $\beta$-actin ( $1: 2000$, A5441, Sigma, St. Louis, MO) respectively, at $4{ }^{\circ} \mathrm{C}$ overnight. The membrane was incubated with the relevant secondary antibody at room temperature for $1 \mathrm{~h}$. Blots were detected using an enhanced chemiluminescence detection system (Millipore, Billerica, MA). The density of target protein normalized to $\beta$-actin was calculated using Image $\mathbf{J}$ software. (National Institutes of Health, Bethesda, MD).

\section{Plasma alanine aminotransferase (ALT) activity}

Plasma ALT activity, an indicator of liver function, was measured using an Alanine Aminotransferase (ALT) Activity Colorimetric Assay Kit (K752, Bio- 
vision, Inc, Milpitas, CA, USA) according to the manufacturer's instructions. We measured the plasma ALT activity for the ETGs and LTGs which were treated with dantrolene for the longest time (11 months). Briefly, $10 \mu \mathrm{l}$ plasma was diluted in a total $100 \mu \mathrm{l}$ reaction mixture, including $86 \mu \mathrm{l}$ ALT Assay Buffer, $2 \mu$ l OxiRed Probe, $2 \mu$ l ALT Enzyme Mix, and $10 \mu \mathrm{l}$ ALT Substrate, to analyze the pyruvate transformed from a-ketoglutarate with alanine. A standard curve was generated at the same time, using pyruvate concentrations of $0,2,4,6,8$, and $10 \mathrm{nmol} /$ well. The optical density (OD) at $570 \mathrm{~nm}$ was measured at $10 \mathrm{~min}$ (A1) then again at $60 \mathrm{~min}$ (A2) after incubating the reaction at $37^{\circ} \mathrm{C}$. The pyruvate concentration was measured in a linear range of the standard curve. ALT activity was calculated using the formulation: ALT activity $=$ $(\mathrm{A} 2-\mathrm{A} 1) / 50 * 10 \mathrm{mU} / \mathrm{ml}$.

\section{Liver histology}

Liver sections $(5 \mu \mathrm{m})$ were imaged for pathological assessment. Three animals from each ETG, with three sections per animal, were selected randomly for pathological assessment and the slides were blinded to the investigators. The sections were stained with hematoxylin and eosin (H\&E) and then imaged on an Olympus BX51W1 microscope. Sections were evaluated for hepatic injuries, such as acute or chronic hepatitis, inflammation, fibrosis, necrosis, cirrhosis, bile stasis, and unspecific hepatocyte abnormities.

\section{Statistical analysis}

The number of animals in each group was determined based on our previous publications [11] and are listed in each figure legend. Statistical analyses were performed with Graph Pad Prism 8.0 and are described in each figure legend. Repeated measures ANOVA was not always possible due to mortality. Data are expressed as means with 95\%CI. It was accepted as a statistically significant difference when $\mathrm{p}$ values were less than or equal to $0.05(p<0.05)$.

\section{RESULTS}

\section{Intranasal delivery increased dantrolene penetration into the brain compared to subcutaneous administration.}

The limited BBB permeability of dantrolene observed after systemic administration has restricted the use and potential effectiveness of the drug [11]. Here, the intranasal administration of dantrolene resulted in lower plasma concentrations, determined at $20 \mathrm{~min}$ after administration, compared to the subcutaneous approach (Fig. 2A). In contrast, the intranasal administration of dantrolene resulted in brain concentrations substantially higher than subcutaneous administration at $60 \mathrm{~min}$ after dosing (Fig. 2B). In combination, the brain/plasma dantrolene concentration ratio (Fig. 2C), a variable often used to indicate drug penetration across the BBB, was significantly higher at both time points after intranasal administration compared to the subcutaneous approach. The integrated overall dantrolene exposure in the brain was significantly higher after intranasal than subcutaneous administration (Fig. 2D, left panels). On the contrast, the integrated overall dantrolene exposure in plasma was significantly lower after intranasal than subcutaneous administration (Fig. 2D, right panels).

\section{Intranasal dantrolene treatment ameliorated memory loss in 5XFAD mice}

Hippocampal-dependent and hippocampalindependent memory were assessed at 6 and 11 months of age, which was after 4 and 9 months of dantrolene treatment in the ETG and after 5 months of treatment in the LTG at 11 months of age. Both measures of cognition were significantly impaired in the 5XFAD controls compared to the WT controls (Supplementary Figure 1) which confirms the aggressive AD phenotype in the 5XFAD model. In 5XFAD mice, intranasal dantrolene treatment significantly improved hippocampal-dependent and independent memory at both 6 and 11 months of age for the ETG group compared to 5XFAD controls without any treatment (Fig. 3). Intranasal dantrolene also significantly ameliorated hippocampal-dependent memory loss at 11 months of age for the LTG and trended to improve hippocampus-independent memory (Fig. 3A, B). Interestingly, the intranasal vehicle also ameliorated hippocampal-dependent memory loss at both 6 and 11 months of age, though it only improved hippocampal-independent memory at 6 months of age in the 5XFAD ETG group. Subcutaneous dantrolene ameliorated both types of memory loss at 6 but not 11 months of age for the ETG groups, nor did it have beneficial effects at 11 months of age for the LTG group (Fig. 3). Dantrolene administration, by either route, had no effect on memory in wild type mice (Supplementary Figure 2). The freezing times for the dantrolene 
A

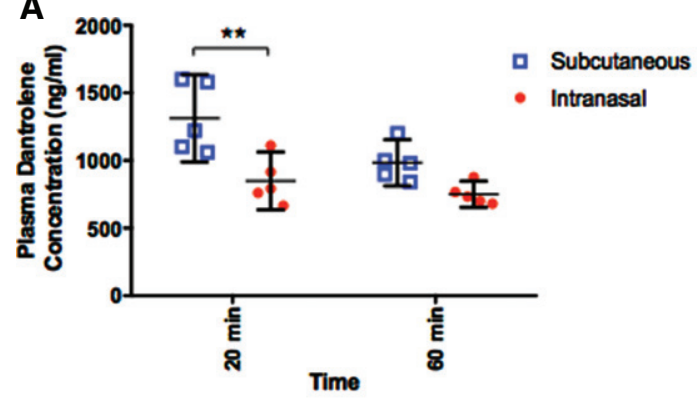

C

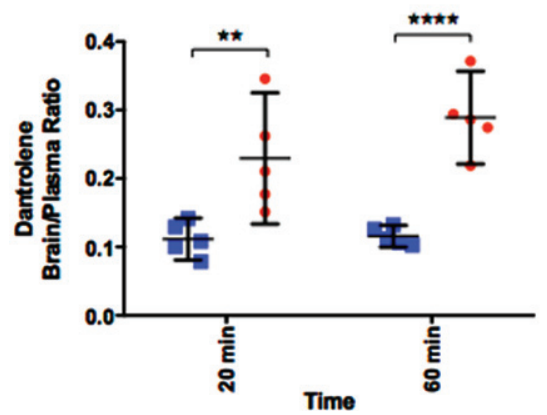

B

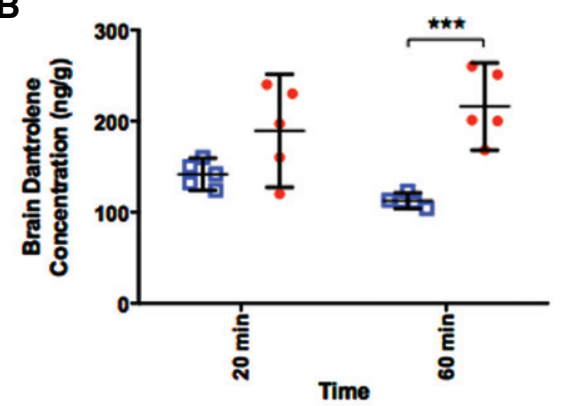

D

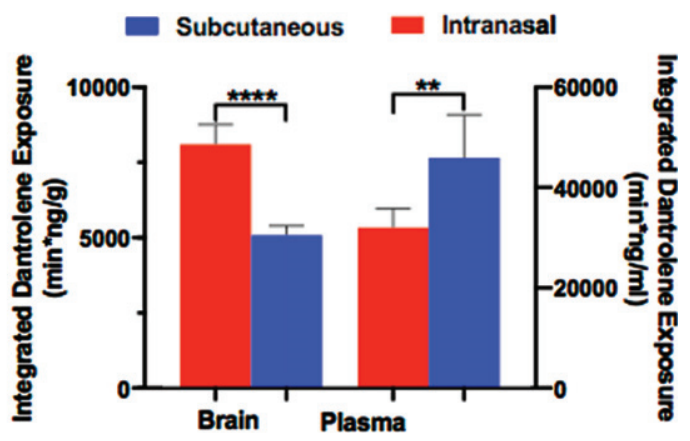

Fig. 2. Intranasal dantrolene provides greater drug penetration into the brain and high brain concentrations. A) Dantrolene concentrations in plasma 20 and $60 \mathrm{~min}$ after subcutaneous (blue) or intranasal (red) administration in B6SJLF1/J mice. There was a significant source of variation in both time $(p=0.015 ; \mathrm{F}(1,16)=7.427)$ and administration route $(p=0.0004 ; \mathrm{F}(1,16)=19.75)$, with an ordinary 2 -way ANOVA. Dantrolene concentration in the plasma was significantly greater at 20 min for subcutaneous administration $(p=0.0014)$ with Sidak's multiple comparisons. B) Brain dantrolene concentrations after the subcutaneous and intranasal approach. There was a significant source of variation for the route of administration $(p<0.0001 ; \mathrm{F}(1,16)=27.07)$ with an ordinary 2-way ANOVA and intranasal dantrolene concentration in the brain was significantly greater at 60 min than subcutaneous administration $(p=0.0002)$ with Sidak's multiple comparisons. C) Dantrolene brain/plasma concentration ratio, representing dantrolene's ability to penetrate the brain. A significant source of variation was found for the route of administration $(p<0.0001 ; \mathrm{F}(1,16)=43.65)$ with an ordinary 2-way ANOVA, and the brain/plasma ratio was significantly greater at both $20 \mathrm{~min}(p=0.0032)$ and $60 \mathrm{~min}(p<0.0001)$ for the intranasal approach, with Sidak's multiple comparisons. D) The area under the curve (AUC) of dantrolene concentrations was also calculated using Linear Trapezoidal Method (Ref) to reflect the integrated overall dantrolene exposure. All data are presented as Mean with $95 \% \mathrm{CI}, \mathrm{N}=5 /$ group for all groups, $* * p<0.01, * * * p<0.001, * * * * p<0.0001$.

treated 5XFAD mice are comparable to the WT freezing times (Supplementary Figure 2), further supporting the improved memory in the transgenic mice.

Hippocampal-dependent learning and memory were examined using the MWM at age 10 months of age for both genotypes. No significant differences were found for the cued trials for all treatment groups compared to controls over time with either the WT or transgenic mice (Supplementary Figure 3A, B). In the place trials, there were no significant differences in the escape latency for all the groups compared to controls, no matter the genotype or the treatment taken as the variate (Supplementary Figure 3C, D). The animals learned the task over time but there were no differences between the treatment groups nor between the genotypes. In the probe trials, there was a significant difference in the TG mice, primarily due to the LTG intranasal dantrolene treatment group compared to control, only in the time spent in the target quadrant (Supplementary Figure 3E) but not the number times the mice crossed the platform (Fig. 3F).

\section{Chronic intranasal and subcutaneous dantrolene treatment was well tolerated}

Dantrolene is a muscle relaxant, so motor function impairment is one of the concerns when it is used for chronic treatment. However, for the 5xFAD mice, we found no significant differences in rotarod performance after 7 months of treatment (ETG) or after 3 months of treatment (LTG), compared with controls (Fig. 4A). Long-term intranasal dantrolene treatment may also damage nasal cells and impair 

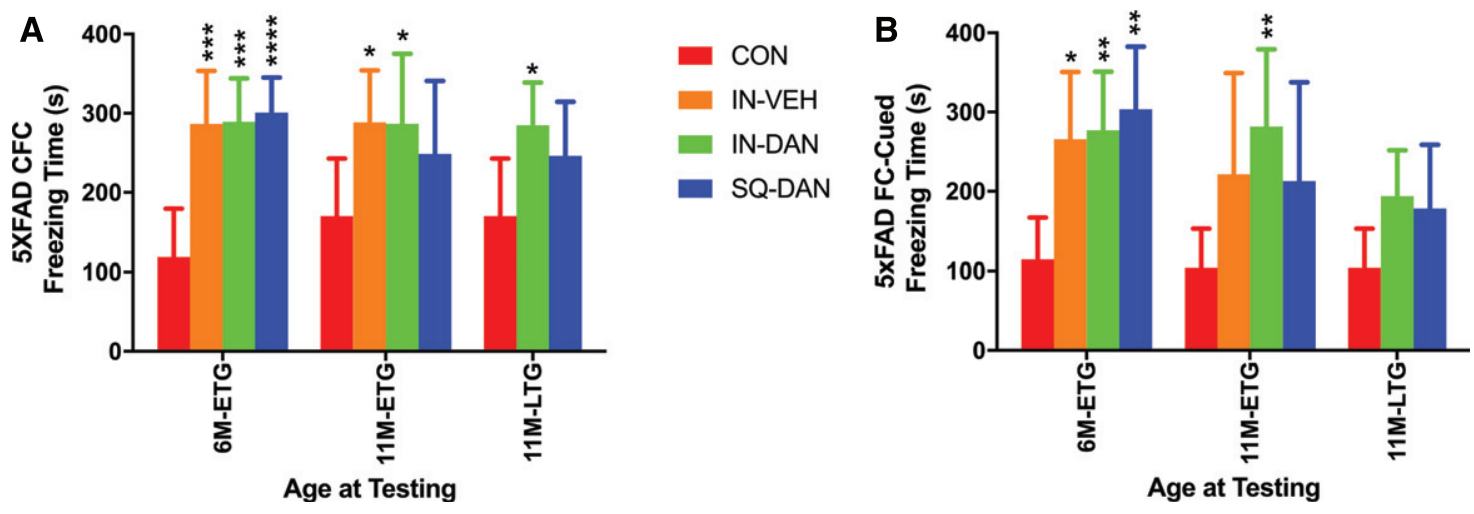

Fig. 3. Intranasal administration of dantrolene had better therapeutic effects on memory in AD mice. Memory was assessed with both contextual fear conditioning (CFC; hippocampus-dependent) and cued fear conditioning (FC-cued; hippocampus-independent) tests. The test was performed after 4 and 9 months of treatment, at $6(6 \mathrm{M})$ and $11(11 \mathrm{M})$ months of age, respectively, for the Early Treatment Group (ETG) and after 5 months of treatment at 11 months of age for the Late Treatment group (LTG). A) With the CFC test, at 6 months of age, all ETG groups, including intranasal administration of vehicle (IN-VEH), dantrolene (IN-DAN), and subcutaneous injection of dantrolene (SQ-DAN) significantly restored memory in the 5XFAD mice compared to untreated controls $(\mathrm{CON})(p=0.0004 ; p=0.0002 ; p<0.0001$, respectively) and actually to WT-CON (data not shown). The memory of 5XFAD mice at 11 months of age was significantly maintained in the IN-VEH and IN-DAN ETG groups ( $p=0.0246, p=0.0228$, respectively). The ETG data were analyzed using the ordinary 2-way ANOVA with Dunnett's multiple comparison test (MCT).Treat was found to be a significant source of variation $(p<0.0001 ; \mathrm{F}(3,49)=9.536)$. At 11 months of age, the LTG (11M-LTG) IN-DAN and SQ-DAN were compared to 5xTG control (CON) and the data were analyzed using the Kruskal-Wallis test with Dunn's MCT. The memory of the In-DAN group was significantly improved compared to CON $(p=0.0410)$. The memory of the SQ-DAN trended to be better but not statistically significant $(p=0.1575)$. B) Similarly, hippocampus-independent memory (FC-cued), at 6 months of age, was significantly improved in the ETG with IN-VEH $(p=0.0145)$, IN-DAN $(p=0.0055)$, and SQ-DAN $(p=0.001)$ compared to controls. At 11 months of age, the memory of the IN-DAN group was still significantly better $(p=0.0011)$ than the CON group, analyzed using the ordinary 2-way ANOVA with Dunnett's multiple comparison test (MCT). Treatment was found to be a significant source of variation $(p=0.0013 ; \mathrm{F}(3,49)=6.095)$. IN-VEH or SQ-DAN trended to improve memory but were not statistically different ( $p=0.0664, p=0.1843$, respectively). No significant memory improvement was detected in the LTG group at 11 months in the IN-DAN or SQ-DAN group compared to 5xFAD CON usingthe Kruskal-Wallis test with Dunn's MCT.All data are presented as Mean with $95 \% \mathrm{CI}, * p<0.05, * * p<0.01, * * * p<0.001, * * * * p<0.0001$, compared to 5xFAD CON. Animal numbers, ETG 6M: CON $n=13$, IN-VEH $n=12$, IN-DAN $n=14$, IN-SQ $n=14$; ETG $11 \mathrm{M}$ : CON $n=13$, IN-VEH $n=10$, IN-DAN $n=11$, IN-SQ $n=9$; LTG $11 \mathrm{M}$ : IN-DAN $n=13$, SQ-DAN $n=14, \mathrm{CON}=13$, same controls as shown for ETG $11 \mathrm{M}$ ).

olfaction. We found that the sense of smell was not significantly impaired after 6 months of intranasal treatment (ETG) or after 2 months of treatment (LTG) in the transgenic mice (Fig. 4B). Previous studies have demonstrated that oral dantrolene, at a high dose for prolonged use, may impair liver function [7]. In this study, dantrolene treatment, either intranasal or subcutaneous, for 10 months (ETG) had no significant effect on liver function or liver structure in the 5XFAD mice (Fig. 4C, D). Furthermore, chronic intranasal or subcutaneous dantrolene treatment for up to 10 months did not affect mortality rates or body weight in either group of transgenic mice (Fig. 4E, F). In wild type mice, there were no significant differences in olfaction, motor function, mortality, or body weight (Supplementary Figure 4A-C, E, F). While we did detect a significant increase in the liver enzyme, alanine aminotransferase, in WT mice after 10 months of treatment (ETG), the values were still within the normal physiological range (Supplementary Figure 4D) [27].

\section{Dantrolene treatment did not reduce the amyloid load in the hippocampus and cortex of $5 X F A D$ mice}

The number of amyloid plaques and the area occupied by the plaques was determined and analyzed in both the hippocampus and the cortex of 5XFAD mice (Fig. 5). Neither intranasal nor subcutaneous dantrolene treatment altered the amyloid load significantly in the hippocampus or cortex in 5XFAD mice (Fig. 5). No amyloid load was detected in WT mice (Supplementary Figure 5).

\section{No significant differences were found in synaptic function-related proteins}

The expression of PSD95 and synapsin1 from the whole brain were determined and analyzed for the ETG and LTG. There were no significant differences between the treatment groups and controls for either genotype (Supplementary Figure 6). 
A

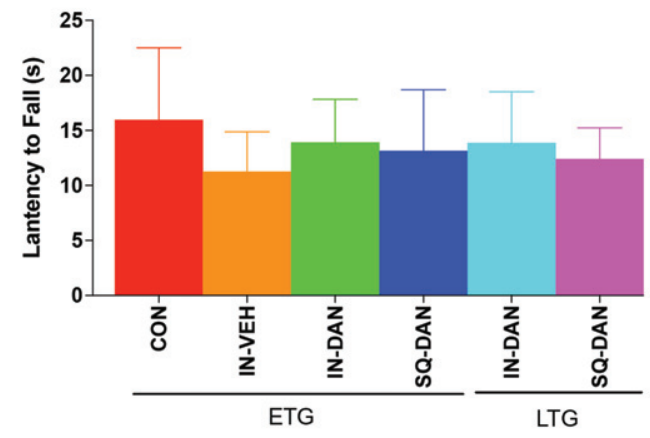

C

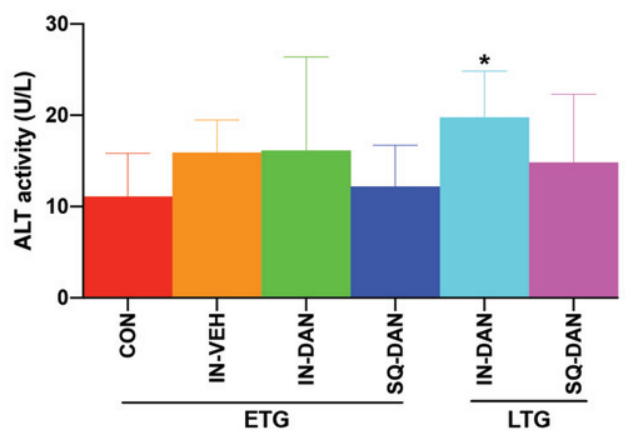

E

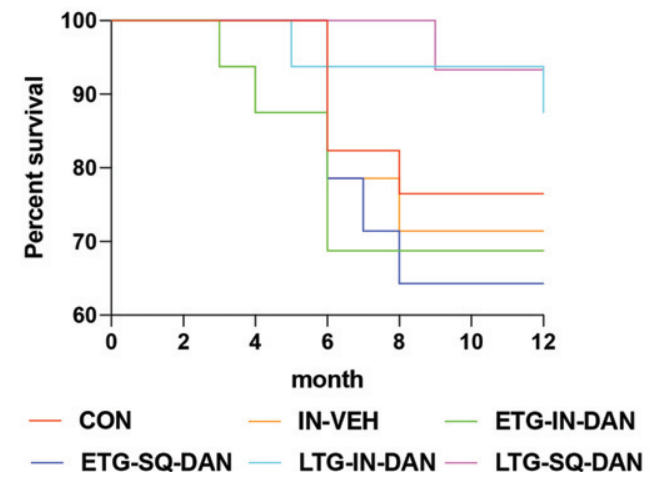

B

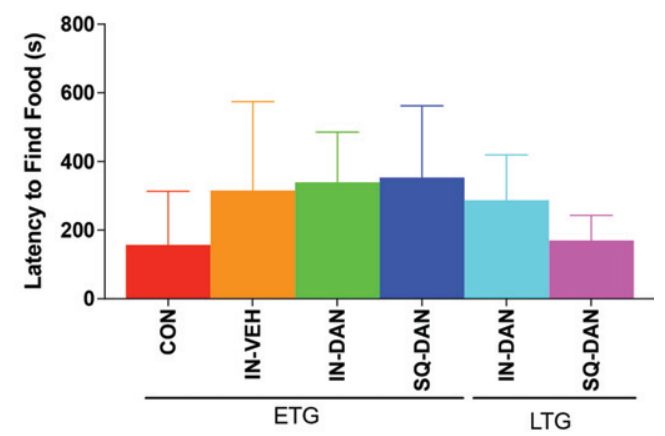

D

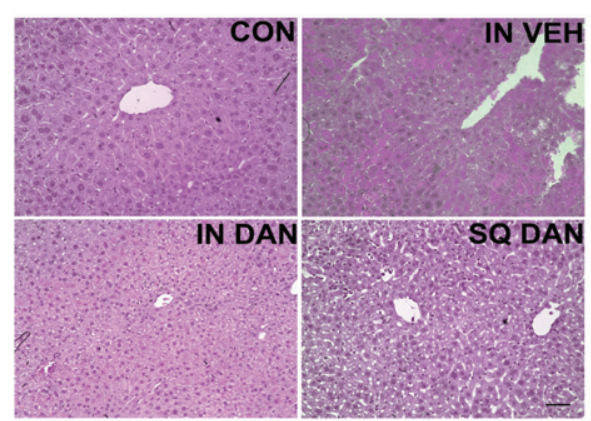

$\mathbf{F}$

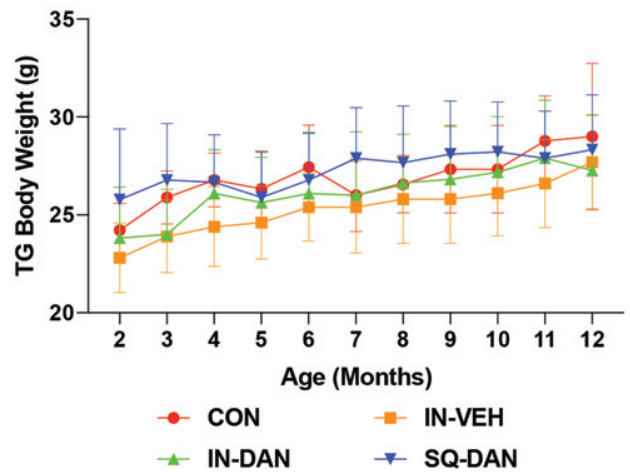

Fig. 4. Side effects of long-term dantrolene treatment. Intranasal administration of dantrolene (IN-DAN) or vehicle (IN-VEH) and subcutaneous administration of dantrolene (SQ-DAN) were administered $3 \times /$ week starting at 2 months of age for the early treatment group (ETG) and at 6 months of age for the late treatment group (LTG). A) Motor function was measured using the rotarod test for all groups at 9 months of age. No significant differences between the treatment groups and the control group were detected with the ordinary one-way ANOVA and Dunnett's multiple comparison test (MCT). (ETG: CON $n=13$, IN-VEH $n=10$, IN-DAN $n=11$, SQ-DAN $n=9$; LTG: IN-DAN $n=13$, SQ-DAN $n=15$.) B) Olfaction was measured using the food buried test for all groups at 10 months of age. No significant differences were found with the Kruskall-Wallis test for nonparametric data and Dunn's MCT. (ETG: CON $n=13$, IN-VEH $n=10$, IN-DAN $n=10$, SQ-DAN $n=9$; LTG: IN-DAN $n=13$, SQ-DAN $n=15$.) C) Liver function was evaluated for the ETG and LTG by measuring plasma alanine aminotransferase (ALT) activity. ALT was significantly increased after 6-month intranasal treatment in LTG compared to control group $(p=0.0364)$. No significant differences were detected between other treatment groups and the control group with the Kruskall-Wallis test for nonparametric data and Dunn's MCT. (ETG: CON $n=9$, IN-VEH $n=9$, IN-DAN $n=8$, SQ-DAN $n=8$, LTG: IN-DAN $n=9$, SQ-DAN $n=7)$. All data are presented as Mean with $95 \%$ CI. D) Hepatic pathology was examined at 11 months of age in H\&E stained sections of the ETG mice. No gross differences were observed between ETG groups ( 3 sections/animal: CON $n=3$, IN-VEH $n=3$, IN-DAN $n=3$, SQ-DAN $n=3$, bar $=50 \mu \mathrm{m}$ ). E) Mortality after chronic treatment (ETG, LTG) with dantrolene (IN-DAN, SQ-DAN) or vehicle (IN-VEH) was compared to untreated 5XFAD controls using the Log-rank (Mantel-Cox) test. No significant difference between dantrolene and vehicle treatments was detected $(p=0.3636)$. F) Bodyweight was monitored during the treatment. No significant differences were detected in the growth curve for the 5XFAD mice in the ETG groups $(p=0.1478)$ with repeated measures 2-way ANOVA. (ETG: CON $n=13$, IN-VEH $n=10$, IN-DAN $n=11$, SQ-DAN $n=9$; LTG: IN-DAN $n=14$, SQ-DAN $n=14$.)All data are presented as Mean with $95 \%$ CI. 
A

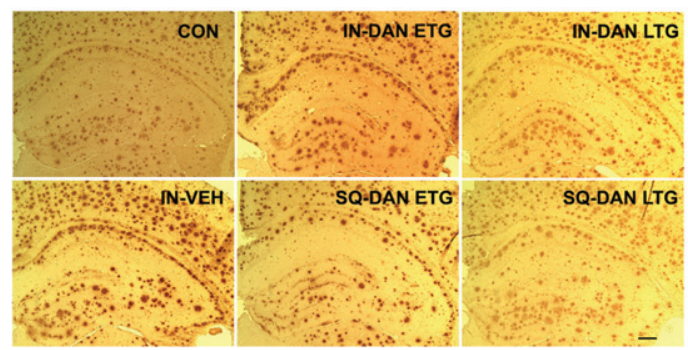

C

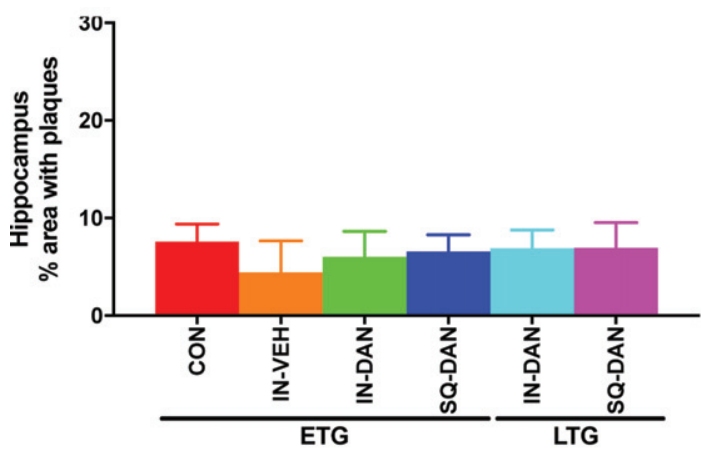

E

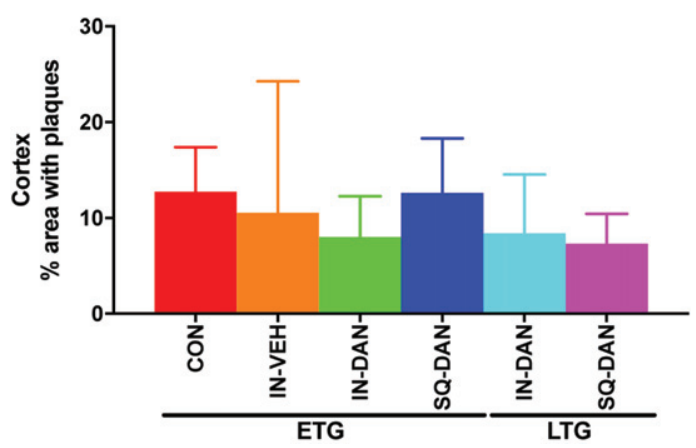

B

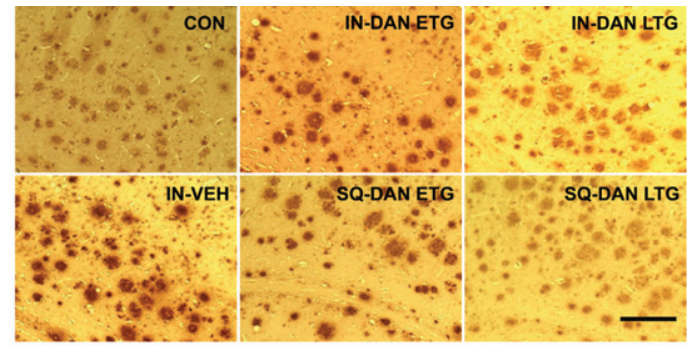

D

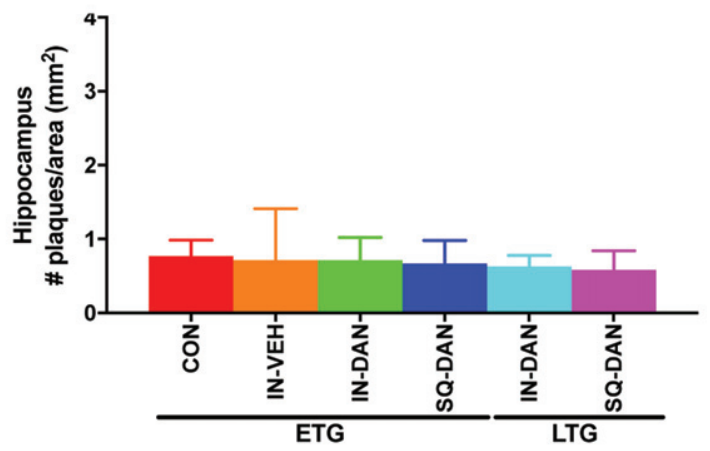

$\mathbf{F}$

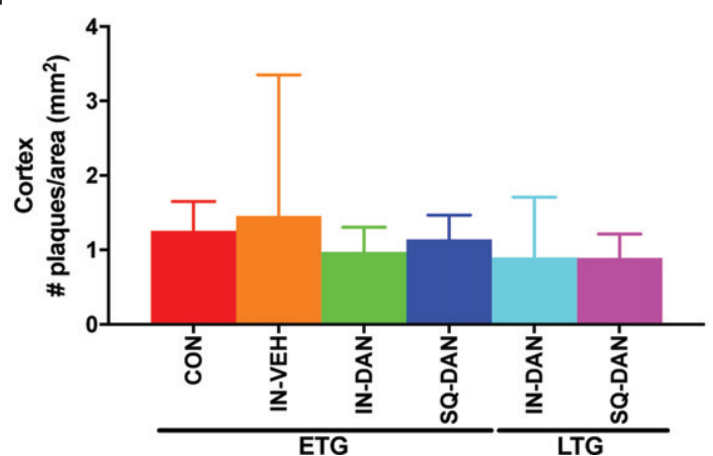

Fig. 5. Dantrolene had no significant effects on amyloid plaque levels in the dentate gyrus and hippocampus of 5XFAD mice. A, B) Representative micrographs of 6E10 immunoreactivity in the hippocampus and cortex of 5XFAD mice in the Early Treatment Group (ETG) and Late Treatment groups (LTG) including, control (CON), intranasal vehicle (IN-VEH), intranasal dantrolene (IN-DAN), and subcutaneous dantrolene (SQ-DAN). (Bar $=100 \mu \mathrm{m})$. C, E) The percent area of the hippocampus and cortex occupied by plaques was calculated for the ETG and LTG. No significant differences were found between the treatment groups and control. D, F) Similarly, the number of amyloid plaques per area $\left(\mathrm{mm}^{2}\right)$ was calculated in the hippocampus and cortex for the ETG and LTG and no significant differences were found. All data were analyzed with the Kruskall-Wallis test for nonparametric data and Dunn's MCT. (3 sections/animal; DG and HIP, ETG: CON $n=8$, IN-VEH $n=4$, IN-DAN $n=6$, SQ-DAN $n=6$; LTG: IN-DAN $n=6$, SQ-DAN $n=7$ ). Data are presented as Mean with $95 \%$ CI.

\section{DISCUSSION}

We have demonstrated in an aggressive model of AD that chronic intranasal dantrolene treatment improved memory, even when treatment was started after the onset of apparent AD neuropathology and cognitive dysfunction. Intranasal dantrolene treatment showed disease-modifying properties without obvious adverse effects on motor coordination, olfac- tion, liver function, and mortality in 5XFAD mice. The greater dantrolene penetration into the brain, as evidenced by the higher brain concentrations after intranasal administration, compared to the subcutaneous approach, is consistent with its therapeutic effects on memory improvement in 5XFAD mice. This supports our previous study [24], providing further evidence of improved CNS penetration with the intranasal administration of dantrolene and its 
potential superior therapeutic effect on cognitive dysfunction, rendering intranasal dantrolene as a potential new drug treatment for $\mathrm{AD}$.

Dantrolene has been demonstrated to be neuroprotective in many neurodegenerative diseases, including cerebral ischemia [28, 29], Alzheimer's disease [9, 11, 12], Huntington's disease [15], spinocerebellar ataxia type 3 [30], seizure [31], and trauma [32]. However, the limited ability of dantrolene to pass the BBB in different animal models, including monkey $[14,30]$, has dampened the excitement for the use of dantrolene as a potential neuroprotective drug. Many studies have suggested that intranasal drug administration, in comparison to the commonly used oral, IV, or subcutaneous approaches, increased drug penetration into the CNS, resulting in greater drug exposure [17]. However, no studies have investigated whether intranasal dantrolene can facilitate its passage into the CNS and increase dantrolene concentrations in the brain. In this study, we found increased brain concentrations of dantrolene with the concomitant decrease in plasma concentrations at 20 and $60 \mathrm{~min}$ after intranasal administration, compared to the subcutaneous approach. This suggests that intranasal delivery provides better penetration into the brain than the subcutaneous approach. We have also found the intranasal dantrolene approach increased peak brain concentrations and prolonged the duration in the brain over the oral approach, but did not significantly increase its ability to pass the BBB [24]. Further studies are needed to establish the brain and plasma dantrolene pharmacokinetics to confirm that the intranasal administration consistently provides overall greater brain exposure than the subcutaneous, intravenous, or oral approaches. The benefit of the increased brain compared to plasma with the intranasal approach is the reduced therapeutic dose, thereby minimizing peripheral side effects. Considering dantrolene's dose-dependent effects on neuroprotection in other neurodegenerative diseases [29], intranasal dantrolene is also expected to provide better therapeutic effects with few side effects in these diseases. It should be noted the therapeutic dose of dantrolene would need to be worked out for each disease [33].

Our previous study indicated that oral dantrolene treatment initiated before the onset of amyloid pathology or cognitive dysfunction at 2 months of age abolished memory loss in 13-month-old3XTGAD mice [11]. However, our recent study [34] investigating the therapeutic effects of oral dantrolene initiated at 9 months of age in 3XTGAD mice, after the onset of AD pathology and cognitive dysfunction, did not result in significant improvement at 15 months of age. The fact that the aged 3XTGAD mice in that study did not show impaired memory compared to WT controls, similar to our previous study in 3xTG-AD mice [34], suggested that the MWM was not sensitive enough to examine cognitive function in old mice. Likewise, in this study, the MWM test also did not detect a significant difference in cognitive function between WT and 5XFAD control mice at 10 months of age (Supplementary Figure 3) further suggesting, as reported in another study [34,35], the low sensitivity of the MWM to determine learning and memory changes in 4F. MWM test is not recommended to be the only or the primary test for examining cognitive dysfunction in aged mice. On the other hand, the fear conditioning tests that shown here demonstrated decreased hippocampal-dependent and -independent memory in 11-month-old control 5XFAD mice compared to WT, consistent with a recent study suggesting fear conditioning is a more sensitive cognitive test to detect memory impairment in aged mice [35]. Furthermore, we found that only the intranasal administration of dantrolene improved memory when the treatment was initiated after the onset of AD pathology and cognitive dysfunction. This suggests that dantrolene may be an effective disease-modifying drug, which is consistent with intranasal dantrolene's more efficient penetration into the brain. These results are clinically important because effective diagnostic methods for $\mathrm{AD}$ at an early stage are just emerging and $\mathrm{AD}$ is commonly diagnosed after the onset of cognitive dysfunction. Thus, effective treatment after the onset of memory loss makes intranasal dantrolene a promising therapeutic for AD patients. Another advantage of the intranasal administration of dantrolene is its ease of use and convenience for patients, compared to other modes of administration.

It is important to develop a new drug that is effective to treat patients with sporadic Alzheimer's disease (SAD), as it contributes to $95 \%$ of all $\mathrm{AD}$ patients. Although the mechanisms of SAD are not clear, a recent study suggested that ryanodine receptor over activation or pathological "ryanodine receptor $\mathrm{Ca}^{2+}$ leaking" due to posttranslational RyR phosphorylation by protein kinase A (PKA) and/or deletion of calstabin 2 contributes to the pathology and cognitive dysfunction in SAD [5, 36, 37]. Our recent study demonstrated that RyR proteins were abnormally elevated in induced pluripotent stem cells and 
derived neurons from SAD patients and that dantrolene ameliorated the impairment of neurogenesis and synaptogenesis in these cells [38]. Therefore, the ability of dantrolene to inhibit RyR channel opening as the receptor antagonist has the potential to ameliorate the pathology and memory loss in SAD patients.

However, in this study, intranasal dantrolene treatment initiated either before or after the onset of AD pathology and cognitive dysfunction did not affect extracellular plaque in 5XFAD mice. Previous studies have demonstrated both increased [8] and decreased $[9,11,12]$ amyloid aggregation or plaque formation in various FAD mice after dantrolene treatment. Nevertheless, amyloid aggregation or plaque formation may contribute to AD pathology but may not be the primary cause of synapse and cognitive dysfunction. Older people may have obvious amyloid plaques without cognitive dysfunction. There also has been some controversy about whether amyloid is the only pathology contributing to AD dementia [39]. After decades of new drug developments, primarily targeting amyloid pathology, no effective drug therapy for $\mathrm{AD}$ has become available, despite reductions in plaques [2]. Emerging mechanisms for cognitive dysfunction in AD include tauopathy, neuroinflammation, oxidative stresses, cell cycle dysfunction, or impaired neurogenesis $[39,40]$. Calcium dysregulation plays an important role in neurodegeneration, impaired neurogenesis, synaptic damage and dysfunction, and cognitive dysfunction, which can all be ameliorated or abolished with dantrolene treatment [9, 11, 12, 41-43]. Furthermore, Calcium dysregulation may be upstream, triggering signals for $\mathrm{AD}$ pathological inflammation and oxidative stress, etc., which can also be ameliorated by dantrolene [44-46]. Overall, disruption of calcium homeostasis, by excessive activation of both NMDA glutamate receptors and RyRs, maybe a common upstream mechanism in various neurodegenerative diseases, and a more effective drug target, independent of amyloid load, as supported by the data in this study [4].

There are several possible mechanisms for the therapeutic effects of dantrolene on AD. 1) During the progression of $\mathrm{AD}$ pathology, multiple pathways including ER and mitochondrial damage, production of reactive oxygen species, inflammation, impaired neurogenesis contribute to AD synaptic and cognitive dysfunction. Over activation of the ryanodine receptor and the abnormal calcium leakage from the ER may be an upstream pathway for these multiple pathologies. Amelioration of RyR over activation by dantrolene has been demonstrated to be pro- tective against these multiple pathology pathways [44, 46-48]. 2) Intracellular calcium homeostasis plays an important role in the maintenance of normal synaptic function. Ryanodine over activation and excessive calcium release from the ER in AD contributes to synaptic dysfunction. Thus, dantrolene can restore synaptic function by correcting the calcium dysfunction [49, 50]. 3) Impaired neurogenesis and synaptogenesis via over activation of RyRs and associated calcium dysregulation contributes to synaptic and cognitive dysfunction, which can be ameliorated by dantrolene [38].

Because $\mathrm{AD}$ is a chronic neurodegenerative disease, any new effective therapeutic drug must also have tolerable side effects with long-term use. Dantrolene is used chronically in patients to treat muscle spasms without significant side effects [7]. However, if used at very high doses, itcan cause liver toxicity [19]. Our previous study demonstrated that oral dantrolene at $5 \mathrm{mg} / \mathrm{kg}$, three times a week for up to 11 months, did not cause significant muscle weakness in 3XTGAD mice [11]. The data presented here indicated that intranasal or subcutaneous dantrolene at $5 \mathrm{mg} / \mathrm{kg}, 3$ times/week for up to 10 months, did not adversely affect olfaction, motor function, liver structure and function, mortality, or body weight in 5XFAD mice, further strengthening the safety for the chronic use of dantrolene. Intranasal dantrolene tended to lower the mortality in 5XFAD mice, although not statistically significant (Fig. 4E). Although chronic intranasal dantrolene increased liver function enzymes in wild type mice, the levels are still within the normal physiological range (Supplementary Figure 4C). Furthermore, because the neuroprotective effect of dantrolene is dose-dependent [29], the higher brain concentrations and lower plasma concentrations after intranasal administration, relatively to subcutaneous approach, may allow even lower intranasal dantrolene doses while still maintaining effective therapy. Considering that dantrolene is already an FDA approved drug for the treatment of malignant hyperthermia and muscle spasms [7, 29], intranasal dantrolene therapy may be a good candidate for clinical trials to treat $\mathrm{AD}$ patients in the future.

This study has the following limitations: 1) The study design did not include an intranasal vehicle for the LTG groups as, based on our previous studies, we did not expect the protective effects of intranasal vehicle. Similarly, we did not have a control group for mouse handling, which may have explained why the intranasal vehicle group also ameliorated memory 
loss in 5XFAD mice in the early treatment groups. However, only intranasal, but not subcutaneous, dantrolene, improved memory in the late treatment group, which suggests that since all of the animals were handled except for the controls, the memory improvement was more likely due to dantrolene and not due to handling. 2) The effects of dantrolene on neurodegeneration, inflammation, or oxidative stress in 5XFAD mice were not examined in this study but are planned in a future study. 3) The study was not designed to measure the concentration of dantrolene in the brain after chronic treatment because not enough brain tissue could be achieved for the pathology and biochemical studies as well as dantrolene concentration measurements. 4) The dantrolene concentrations in the brain were conducted in young adult B6SJLF1/J mice and not aged transgenic mice. 5) Limited time points to assess the pharmacokinetics between intranasal delivery and subcutaneous administration. 6) Though a previous study reported that dantrolene inhibited the loss of synaptic proteins [9], we did not see a similar effect in 5XFAD mice but did not measure all synaptic proteins.

\section{CONCLUSIONS}

The long-term intranasal administration of dantrolene had therapeutic effects on memory compared to the subcutaneous approach, suggesting as a disease-modifying drug, without significant effects on amyloid plaques, side effects, or mortality. Taken together, intranasal dantrolene is a viable drug for the treatment of $\mathrm{AD}$ and other dementias.

\section{ACKNOWLEDGMENTS}

This work was supported by grants to HW from the National Institute of General Medical Sciences (R01GM084979) and the National Institute on Aging (R01AG061447). The research was performed in the lab of Dr. Huafeng Wei and should be attributed to the Department of Anesthesiology, University of Pennsylvania. We appreciate the valuable discussion with Dr. Roderic Eckenhoff from the Department of Anesthesiology and Critical Care and Dr. Joel D. Cooper from the Department of Surgery, University of Pennsylvania, Philadelphia, PA, USA.

The results of this manuscript have been included in a US provisional patent application titled "Intranasal Administration of Dantrolene for Treatment of Alzheimer's Disease" filed on June 28, 2019
(Serial number $62 / 868,820$ ) by the University of Pennsylvania Trustee. Four of the co-authors, all employees of the University of Pennsylvania, Drs. Huafeng Wei, Qing cheng Meng, Ge Liang, and Maryellen Eckenhoff, are listed as inventors of the provisional patent application. The patent application is also part of the research collaboration agreement between the University of Pennsylvania and Eagle Pharmaceutical Company, which produces and sells a new formula of dantrolene (Ryanodex) for the treatment of malignant hyperthermia.

A.H. is the Chief Medical Officer of Eagle Pharmaceuticals, the manufacturer of Ryanodex (dantrolene sodium). The dantrolene and vehicle chemicals used in this study were purchased from Millipore Sigma. No materials were provided by Eagle Pharmaceuticals. H.W. was a member of the Advisory Board of Eagle Pharmaceuticals for a one-day meeting in 2017.

Authors' disclosures available online (https:// www.j-alz.com/manuscript-disclosures/20-0227r1).

\section{SUPPLEMENTARY MATERIAL}

The supplementary material is available in the electronic version of this article: https://dx.doi.org/ 10.3233/JAD-200227.

\section{REFERENCES}

[1] Rice DP, Fillit HM, Max W, Knopman DS, Lloyd JR, Duttagupta S (2001) Prevalence, costs, and treatment of Alzheimer's disease and related dementia: a managed care perspective. Am J Manag Care 7, 809-818.

[2] Allgaier M, Allgaier C (2014) An update on drug treatment options of Alzheimer's disease. Front Biosci (Landmark Ed) 19, 1345-1354.

[3] Kelliher M, Fastbom J, Cowburn RF, Bonkale W, Ohm TG, Ravid R, Sorrentino V, O’Neill C (1999) Alterations in the ryanodine receptor calcium release channel correlate with Alzheimer's disease neurofibrillary and beta-amyloid pathologies. Neuroscience 92, 499-513.

[4] Chakroborty S, Goussakov I, Miller MB, Stutzmann GE (2009) Deviant ryanodine receptor-mediated calcium release resets synaptic homeostasis in presymptomatic 3xTg-AD mice. J Neurosci 29, 9458-9470.

[5] Lacampagne A, Liu X, Reiken S, Bussiere R, Meli AC, Lauritzen I, Teich AF, Zalk R, Saint N, Arancio O, Bauer C, Duprat F, Briggs CA, Chakroborty S, Stutzmann GE, Shelanski ML, Checler F, Chami M, Marks AR (2017) Post-translational remodeling of ryanodine receptor induces calcium leak leading to Alzheimer's disease-like pathologies and cognitive deficits. Acta Neuropathol 134, 749-767.

[6] Kolb ME, Horne ML, Martz R (1982) Dantrolene in human malignant hyperthermia. Anesthesiology 56, 254-262.

[7] Krause T, Gerbershagen MU, Fiege M, Weisshorn R, Wappler F (2004) Dantrolene-a review of its pharmacology, 
therapeutic use and new developments. Anaesthesia 59, 364-373.

[8] Zhang H, Sun S, Herreman A, De Strooper B, Bezprozvanny I (2010) Role of presenilins in neuronal calcium homeostasis. J Neurosci 30, 8566-8580.

[9] Oules B, Del Prete D, Greco B, Zhang X, Lauritzen I, Sevalle J, Moreno S, Paterlini-Brechot P, Trebak M, Checler F, Benfenati F, Chami M (2012) Ryanodine receptor blockade reduces amyloid-beta load and memory impairments in $\mathrm{Tg} 2576$ mouse model of Alzheimer disease. J Neurosci 32, 11820-11834.

[10] Peng J, Liang G, Inan S, Wu Z, Joseph D, Meng Q, Peng Y, Eckenhoff M, Wei H (2011) Early and chronic treatment with dantrolene blocked later learning and memory deficits in older Alzheimer's triple transgenic mice. Alzheimers Dement 7, e67.

[11] Peng J, Liang G, Inan S, Wu Z, Joseph DJ, Meng Q, Peng Y, Eckenhoff MF, Wei H (2012) Dantrolene ameliorates cognitive decline and neuropathology in Alzheimer triple transgenic mice. Neurosci Lett 516, 274-279.

[12] Chakroborty S, Briggs C, Miller MB, Goussakov I, Schneider C, Kim J, Wicks J, Richardson JC, Conklin V, Cameransi BG, Stutzmann GE (2012) Stabilizing ER Ca2+ channel function as an early preventative strategy for Alzheimer's disease. PLoS One 7, e52056.

[13] Meyler WJ, Bakker H, Kok JJ, Agoston S, Wesseling H (1981) The effect of dantrolene sodium in relation to blood levels in spastic patients after prolonged administration. $J$ Neurol Neurosurg Psychiatry 44, 334-339.

[14] Wuis EW, Rijntjes NV, Van der Kleijn E (1989) Wholebody autoradiography of 14C-dantrolene in the marmoset monkey. Pharmacol Toxicol 64, 156-158.

[15] Chen X, Wu J, Lvovskaya S, Herndon E, Supnet C, Bezprozvanny I (2011) Dantrolene is neuroprotective in Huntington's disease transgenic mouse model. $\mathrm{Mol} \mathrm{Neu-}$ rodegener $\mathbf{6}, 81$.

[16] Agrawal M, Saraf S, Saraf S, Antimisiaris SG, Chougule MB, Shoyele SA, Alexander A (2018) Nose-to-brain drug delivery: an update on clinical challenges and progress towards approval of anti-Alzheimer drugs. J Control Release 281, 139-177.

[17] Hanson LR, Frey WH, 2nd (2008) Intranasal delivery bypasses the blood-brain barrier to target therapeutic agents to the central nervous system and treat neurodegenerative disease. BMC Neurosci 9 Suppl 3, S5.

[18] Benedict C, Frey WH, 2nd, Schioth HB, Schultes B, Born J, Hallschmid M (2011) Intranasal insulin as a therapeutic option in the treatment of cognitive impairments. Exp Gerontol 46, 112-115.

[19] Chan CH (1990) Dantrolene sodium and hepatic injury. Neurology 40, 1427-1432.

[20] Oakley H, Cole SL, Logan S, Maus E, Shao P, Craft J, Guillozet-Bongaarts A, Ohno M, Disterhoft J, Van Eldik L, Berry R, Vassar R (2006) Intraneuronal beta-amyloid aggregates, neurodegeneration, and neuron loss in transgenic mice with five familial Alzheimer's disease mutations: potential factors in amyloid plaque formation. $J$ Neurosci 26, 10129-10140.

[21] Richard BC, Kurdakova A, Baches S, Bayer TA, Weggen S, Wirths O (2015) Gene dosage dependent aggravation of the neurological phenotype in the 5XFAD mouse model of Alzheimer's disease. J Alzheimers Dis 45, 1223-1236.

[22] Hillmann A, Hahn S, Schilling S, Hoffmann T, Demuth HU, Bulic B, Schneider-Axmann T, Bayer TA, Weggen S, Wirths O (2012) No improvement after chronic ibuprofen treat- ment in the 5XFAD mouse model of Alzheimer's disease. Neurobiol Aging 33, 833 e839-e850.

[23] Hanson LR, Fine JM, Svitak AL, Faltesek KA (2013) Intranasal administration of CNS therapeutics to awake mice. $J$ Vis $\operatorname{Exp} 74$, e 4440

[24] Wang J, Shi Y, Yu S, Wang Y, Meng Q, Liang G, Eckenhoff MF, Wei H (2020) Intranasal administration of dantrolene increased brain concentration and duration. PLoS One. 15, e0229156.

[25] Yang M, Crawley JN (2009) Simple behavioral assessment of mouse olfaction. Curr Protoc Neurosci Chapter 8, Unit 8.24 .

[26] Zhang Y, Xu Z, Wang H, Dong Y, Shi HN, Culley DJ, Crosby G, Marcantonio ER, Tanzi RE, Xie Z (2012) Anesthetics isoflurane and desflurane differently affect mitochondrial function, learning, and memory. Ann Neurol 71, 687-698.

[27] Lam K, Chan C, Done SJ, Levine MN, Reilly RM (2015) Preclinical pharmacokinetics, biodistribution, radiation dosimetry and acute toxicity studies required for regulatory approval of a clinical trial application for a phase I/II clinical trial of (111)In-BzDTPA-pertuzumab. Nucl Med Biol 42, 78-84.

[28] Wei H, Perry DC (1996) Dantrolene is cytoprotective in two models of neuronal cell death. J Neurochem 67, 2390-2398.

[29] Inan S, Wei H (2010) The cytoprotective effects of dantrolene: a ryanodine receptor antagonist. Anesth Analg 111, 1400-1410.

[30] Chen X, Tang TS, Tu H, Nelson O, Pook M, Hammer R, Nukina N, Bezprozvanny I (2008) Deranged calcium signaling and neurodegeneration in spinocerebellar ataxia type 3. J Neurosci 28, 12713-12724.

[31] Nagatomo I, Hashiguchi W, Tominaga M, Akasaki Y, Uchida M, Takigawa M (2001) Effects of MK-801, dantrolene, and FK506 on convulsive seizures and brain nitric oxide production in seizure-susceptible EL mice. Brain Res 888, 306-310.

[32] Aslan A, Cemek M, Buyukokuroglu ME, Altunbas K, Bas O, Yurumez Y, Cosar M (2009) Dantrolene can reduce secondary damage after spinal cord injury. Eur Spine J 18, 1442-1451.

[33] Yang M, Wang Y, Liang G, Xu Z, Chu CT, Wei H (2019) Alzheimer's disease presenilin-1 mutation sensitizes neurons to impaired autophagy flux and propofol neurotoxicity: role of calcium dysregulation. JAlzheimers Dis 67, 137-147.

[34] Wu Z, Yang B, Liu C, Liang G, Eckenhoff MF, Liu W, Pickup S, Meng Q, Tian Y, Li S, Wei H (2015) Longterm dantrolene treatment reduced intraneuronal amyloid in aged Alzheimer triple transgenic mice. Alzheimer Dis Assoc Disord 29, 184-191.

[35] Neuner SM, Heuer SE, Huentelman MJ, O'Connell KMS, Kaczorowski CC (2019) Harnessing genetic complexity to enhance translatability of Alzheimer's disease mouse models: a path toward precision medicine. Neuron 101, 399-411.e35.

[36] Wang Y, Shi Y, Wei H (2017) Calcium dysregulation in Alzheimer's disease: a target for new drug development. $J$ Alzheimers Dis Parkinsonism 7, 374.

[37] Shi Y, Wang Y, Wei H (2019) Dantrolene: from malignant hyperthermia to Alzheimer's disease. CNS Neurol Disord Drug Targets 18, 668-676.

[38] Wang Y, Liang G, Liang S, Mund R, Shi Y, Wei H (2020) Dantrolene ameliorates impaired neurogenesis and synaptogenesis in induced pluripotent stem cell lines derived from patients with Alzheimer's disease. Anesthesiology 132, 1062-1079. 
[39] Castellani RJ, Lee HG, Siedlak SL, Nunomura A, Hayashi T, Nakamura M, Zhu X, Perry G, Smith MA (2009) Reexamining Alzheimer's disease: evidence for a protective role for amyloid-beta protein precursor and amyloid-beta. $J$ Alzheimers Dis 18, 447-452.

[40] Mu Y, Gage FH (2011) Adult hippocampal neurogenesis and its role in Alzheimer's disease. Mol Neurodegener 6, 85.

[41] Makarewicz D, Zieminska E, Lazarewicz JW (2003) Dantrolene inhibits NMDA-induced 45Ca uptake in cultured cerebellar granule neurons. Neurochem Int 43, 273-278.

[42] Wang JM, Sun C (2010) Calcium and neurogenesis in Alzheimer's disease. Front Neurosci 4, 194.

[43] Chakroborty S, Kim J, Schneider C, West AR, Stutzmann GE (2015) Nitric oxide signaling is recruited as a compensatory mechanism for sustaining synaptic plasticity in Alzheimer's disease mice. J Neurosci 35, 6893-6902.

[44] Nemeth ZH, Hasko G, Szabo C, Salzman AL, Vizi ES (1998) Calcium channel blockers and dantrolene differentially regulate the production of interleukin-12 and interferon-gamma in endotoxemic mice. Brain Res Bull 46, 257-261.

[45] Conrad DM, Hanniman EA, Watson CL, Mader JS, Hoskin DW (2004) Ryanodine receptor signaling is required for anti-CD3-induced $\mathrm{T}$ cell proliferation, interleukin-2 synthesis, and interleukin-2 receptor signaling. J Cell Biochem 92 , 387-399.
[46] Wei H, Leeds P, Chen RW, Wei W, Leng Y, Bredesen DE, Chuang DM (2000) Neuronal apoptosis induced by pharmacological concentrations of 3-hydroxykynurenine: characterization and protection by dantrolene and $\mathrm{Bcl}-2$ overexpression. J Neurochem 75, 81-90.

[47] Hopp SC, D'Angelo HM, Royer SE, Kaercher RM, Crockett AM, Adzovic L, Wenk GL (2015) Calcium dysregulation via L-type voltage-dependent calcium channels and ryanodine receptors underlies memory deficits and synaptic dysfunction during chronic neuroinflammation. J Neuroinflammation 12, 56.

[48] Seidlmayer LK, Kuhn J, Berbner A, Arias-Loza PA, Williams T, Kaspar M, Czolbe M, Kwong JQ, Molkentin JD, Heinze KG, Dedkova EN, Ritter O (2016) Inositol 1,4,5-trisphosphate-mediated sarcoplasmic reticulummitochondrial crosstalk influences adenosine triphosphate production via mitochondrial $\mathrm{Ca} 2+$ uptake through the mitochondrial ryanodine receptor in cardiac myocytes. Cardiovasc Res 112, 491-501.

[49] Zhang H, Liu J, Sun S, Pchitskaya E, Popugaeva E, Bezprozvanny I (2015) Calcium signaling, excitability, and synaptic plasticity defects in a mouse model of Alzheimer's disease. $J$ Alzheimers Dis 45, 561-580.

[50] Chakroborty S, Stutzmann GE (2011) Early calcium dysregulation in Alzheimer's disease: setting the stage for synaptic dysfunction. Sci China Life Sci 54, 752-762. 